\title{
Urinary protein markers predict the severity of renal histological lesions in children with mesangial proliferative glomerulonephritis
}

\author{
Yanhong Li ${ }^{1,2}$, Jian Wang ${ }^{1}$, Xueming Zhu ${ }^{1,3}$, Qihua Feng ${ }^{2}$, Xiaozhong $\mathrm{Li}^{2^{*+}}$ and Xing Feng ${ }^{4^{*+}}$
}

\begin{abstract}
Background: Several renal histopathological features, including mesangial hypercellularity, glomerulosclerosis, tubular atrophy and interstitial fibrosis, are considered to be independent predictors of end-stage renal failure in patients with glomerular diseases. Mesangial proliferative glomerulonephritis (MesPGN) is characterized by proliferations of mesangial cells with increase in mesangial matrix and/or deposits in mesangial region. The purpose of this study is to determine the association between urinary protein markers measured at the same time as renal biopsy and the severity of renal histological lesions in children with MesPGN, and to evaluate whether these markers could serve as predictors of severe renal histological lesions in this population.

Methods: Ninety-eight children with MesPGN (40 with IgA nephropathy, 37 with IgM nephropathy, and 21 with MesPGN without IgA/lgM deposition) were enrolled. Urinary level of IgG, albumin, transferrin, a1-microglobulin, $\beta 2$-microglobulin and $\mathrm{N}$-acetyl- $\beta$-glucosaminidase from a morning sample before biopsy was measured. The scores of mesangial hypercellularity, glomerulosclerosis, and tubule-interstitial damage were used to semi-quantitatively evaluate renal histological lesions.

Results: The urine proteins, as independent factors associated with severe mesangial cellularity (> 5 mesangial cells/ mesangial area) were transferrin, albumin, a1-microglobulin, lgG and 24-hour total protein, with severe glomerulosclerosis ( $\geq 10 \%$ glomeruli showing segmental adhesions or sclerosis) were transferrin and 24-hour total protein, and with severe tubule-interstitial damage (focal or diffuse tubular and interstitial lesions) were transferrin and $N$-acetyl- $\beta$-glucosaminidase. Urinary transferrin achieved the area under-the-receiver-operating-characteristic curve (AUC) of 0.86 and 0.82 , respectively, for predicting severe mesangial cellularity and glomerulosclerosis. Urinary $\mathrm{N}$-acetyl- $\beta$-glucosaminidase achieved the highest AUC of 0.82 for predicting severe tubule-interstitial damage. The combination of urinary protein markers, however, did not improve the predictability for renal histological lesions.

Conclusions: Urinary protein markers are useful to predict the severity of renal histological lesions in children with MesPGN, which suggests that urinary proteins might be useful to predict the development and progression of renal histological lesions, and assist in evaluating the outcome and prognosis in children with MesPGN as non-invasive and easily repeatable indicators on the follow-up examination.
\end{abstract}

\footnotetext{
*Correspondence: xiaozhong_|@yahoo.com; xing_feng66@yahoo.com.cn

${ }^{\dagger}$ Equal contributors

${ }^{2}$ Department of nephrology, Children's Hospital of Soochow University,

Suzhou, China

${ }^{4}$ Department of neonatology, Children's Hospital of Soochow University,

Suzhou, China

Full list of author information is available at the end of the article
} 


\section{Background}

Mesangial proliferative glomerulonephritis (MesPGN) is characterized by proliferations of mesangial cells with increase in mesangial matrix and/or deposits in mesangial region [1,2]. IgA nephropathy (IgAN), the classic MesPGN in children, is the most common form of primary glomerulopathy and well-characterized [3-6]. IgAN is a heterogeneous disease ranging from a totally benign condition to rapidly progressive renal failure. From 15 to 40 percent of patients will eventually progress to endstage renal disease (ESRD) $[7,8]$. The clinical course and pathophysiology of non-IgA MesPGN, however, has not been well described. Some investigators suggest that IgM nephropathy (IgMN) is not a distinct clinicopathologic entity, and the presence of mesangial IgM deposition is associated with a poorer treatment and worse outcome [9-11]. MesPGN without immune deposition is suggested to be a distinct type of glomerulopathy with a benign renal prognosis [12].

Accumulating studies have reported clinical, laboratory, and pathological characteristics that predict progressive renal diseases [13-16]. Histopathological features, including glomerulosclerosis, tubular atrophy, interstitial fibrosis and mesangial hypercellularity, were identified as independent predictors of ESRD in both children and adults with glomerular diseases [13,15-21]. The determination of the severity of renal histological damage in the routine follow-up in children with MesPGN may help to identify patients who will subsequently develop ESRD. Unfortunately, renal biopsy is an invasive procedure. It should not be repeatedly performed multiple times in children. Therefore, it is clinically significant to find some non-invasive indicators capable of predicting the severity of renal histological lesions in children with MesPGN.

Over the past decades, urinary protein markers, including urinary IgG, albumin, transferrin, $\alpha 1$-microglobulin, $\beta 2$-microglobulin and $N$-acetyl- $\beta$-glucosaminidase (NAG), have been widely used in clinic to evaluate renal injury in patients with glomerular diseases. A correlation has been demonstrated between extent of various urinary proteins, renal injury and progression to renal insufficiency $[14,22-$ 24]; however, a direct demonstration of various urinary proteins predicting renal histopathological features in children is still lacking. The purpose of this study is to determine the association between urinary protein markers measured at the same time as biopsy and the severity of renal histological lesions in children with MesPGN, and to evaluate whether these markers could serve as predictors of severe renal histological lesions in this population.

\section{Methods}

Patients

A total of 98 children with biopsy-proven MesPGN were included in the study. All children underwent renal biopsy with automated gun under ultrasound guidance at our unit from January 2002 to December 2009. The evaluation of proteinuria was performed at the same time as biopsy. The Institutional Review Board at the Children's Hospital affiliated to Soochow University approved the study. Written informed parental consent was obtained for each child. Exclusion criteria included secondary renal disorders (Henoch-Schönlein purpura nephritis, lupus nephritis, and haemolytic-uraemic syndrome) and biopsies with less than ten glomeruli.

Indications for renal biopsy in patients with primary glomerular diseases at our unit included persistent glomerular hematuria, asymptomatic proteinuria, steroiddependent or -resistant nephrotic syndrome, acute nephritic syndrome presenting with non-classical features, progressive deterioration of renal function, and unexplained chronic kidney disease. The main indication for renal biopsy at our unit was asymptomatic proteinuria with hematuria, because we generally recommend renal biopsy in all these patients. The second main indication is steroid-dependent or-resistant nephrotic syndrome to identify the histopathological type. In the present study, isolated hematuria is the main clinical indication for renal biopsy (43\%), followed by asymptomatic proteinuria with or without hematuria (35\%), steroiddependent or -resistant nephrotic syndrome (19\%) and acute nephritic syndrome (3\%).

\section{Clinical features}

To assess the severity of clinical features, the patients were classified into five categories according to their renal manifestations at the time of biopsy: (1) micro- or macroscopic hematuria; (2) asymptomatic proteinuria with or without hematuria; (3) acute nephritic syndrome; (4) nephrotic syndrome; (5) Acute kidney injury. Classes 1 and 2 were considered as mild clinical features, and classes $3-5$ as severe. Acute nephritic syndrome is defined as hematuria, red blood cell casts, proteinuria, and/or renal insufficiency, and/or hypertension. Nephrotic syndrome is defined as $24-\mathrm{h}$ proteinuria $>40 \mathrm{mg} /$ $\mathrm{m}^{2} / \mathrm{h}$ and serum albumin level $<2.5 \mathrm{~g} / \mathrm{dl}$. Acute kidney injury is defined as $a \geq 50 \%$ decrease in estimated creatinine clearance, based on Schwartz formula.

\section{Histopathological analysis}

All biopsies were examined by light, immunofluorescent and electron microscopy, and reviewed and interpreted by the same pathologists. MesPGN is characterized by proliferations of mesangial cells with increase in mesangial matrix and/or deposits in mesangial region. The diagnosis of MesPGN required the presence of four or more cells per mesangial region. At least $80 \%$ of glomeruli should be involved. The diagnosis of IgAN was based on immunofluorescent and electron microscopy 
sho- wing mesangial deposits of IgA as the predominant or co-dominant immunoglobulin [5,7]. IgMN was defined as primary diffuse MesPGN with IgM being deposited diffusely in the mesangium as the sole or dominant immunoglobulin on immunofluorescent and electron examination [9].

In addition to establishing the diagnosis, the following features for each biopsy were recorded: the number of total glomeruli; the total cell number per glomerulus; the number of mesangial cells; the extent of matrix expansion; the presence of endocapillary hypercellularity, inflammatory cell infiltrate, adhesion, sclerosis and crescent; the severity of tubular atrophy, interstitial inflammation and fibrosis; as well as glomerular immunofluorescent findings for IgA, IgG, IgM, complements C3 and C1q and fibrinogen graded on a scale from 0 to 3 .

\section{Scoring of renal histological lesions}

A semi-quantitative scoring for assessment of mesangial hypercellularity, glomerulosclerosis and tubule-interstitial damage (TID) was developed. Mesangial cellularity (MC) scoring, based on the number of mesangial cells on per mesangial area [15], was graded as: 1 (4-5 cells), 2 (6-7 cells) and 3 ( 8 or more cells). Severe MC is defined as $>5$ mesangial cells/ mesangial area (MC score $\geq 2$ ).

Glomerulosclerosis scoring was adapted from the Oxford Classification of IgA nephropathy $[15,16]$. Glomerulosclerosis, based on the percentage of glomeruli showing segmental adhesions or sclerosis, was scored as: 0 (absent), 1 ( $<10 \%$ of all biopsied glomeruli), 2 (10$25 \%$ glomeruli), 3 (26-50\% glomeruli) and 4 (> $50 \%$ glomeruli). Severe glomerulosclerosis is defined as $\geq 10 \%$ glomeruli showing segmental adhesions or sclerosis (glomerulosclerosis score $\geq 2$ ). "Segmental" means that a lesion involving less than half of the glomerular tuft. Adhesion is defined as an area of continuity between the glomerular tuft and Bowman's capsule with associated extracellular matrix. Sclerosis is defined as obliteration of the capillary lumen by increased extracellular matrix $[15,16,25]$.

TID scoring was adapted from Bazzi et al [26]. The extent of tubular atrophy, interstitial inflammation and interstitial fibrosis was scored as: 0 (absent), 1 (focal, involving $<50 \%$ of the biopsy area), and 2 (diffuse, involving $\geq 50 \%$ of the biopsy area), respectively. The tubular and interstitial scores were summed to obtain a single score for the TID, which was then classified as follows: 0 or 1 , lesions absent or very mildly focal; 2 , focal tubular and interstitial lesion; and 3 or 4, diffuse lesions. Severe TID is defined as focal or diffuse tubular and interstitial lesions (TID score $\geq 2$ ). Tubular atrophy is defined by thick irregular tubular basement membranes with decreased diameter of tubules. Interstitial fibrosis is defined as increased extracellular matrix separating tubules in the cortical area. Interstitial inflammation is defined as inflammatory cells within the cortical interstitium in excess $[15,16]$.

\section{Analysis of urinary protein markers}

For each child, a first morning urine sample was obtained at the day of biopsy. Urinary level of IgG, albumin, transferrin, $\alpha 1$-microglobulin and $\beta 2$-microglobulin were measured on an automatic biochemical analyzer (HITACHI 7600, Tokyo, Japan), and expressed in milligrams per gram of urinary creatinine $(\mathrm{mg} / \mathrm{g} \mathrm{uCr})$. On HITACHI 7600, urinary NAG was measured using a colorimetric assay with 3 -cresolsulfonphthaleyn- $\mathrm{N}$-acetyl- $\beta$ $\mathrm{D}$-glucosaminide as a substrate, and expressed in unit per gram of urinary $\mathrm{Cr}(\mathrm{u} / \mathrm{g} \mathrm{uCr})$. Urinary $\mathrm{Cr}$ was measured automatically by the Jaffe's method without deproteinization. In addition, 24-hour urinary excretion of total protein (24-h proteinuria, $\mathrm{mg} / \mathrm{m}^{2} / \mathrm{h}$ ) was measured by Coomassie blue method.

In addition, serum level of creatinine, urea nitrogen, total protein, albumin, cholesterol, triglyceride, immunoglobulins (IgA, IgG and IgM) and complements (C3 and C4) were recorded for each child.

\section{Statistical analysis}

Statistical analyses were performed using SPSS Statistics 13.0. Assumptions of normality and homogeneity of variance were first checked. For continuous variables with a normal distribution, descriptive results were presented as a mean and a standard deviation (SD). The $\mathrm{t}$ test for unpaired samples and the one-way ANOVA were used to analyze the differences among groups. For continuous variables with a skewed distribution, descriptive results were expressed as a median and a range. The Mann-Whitney U-test and the Kruskal-Wallis test were used to analyze the difference among groups. Categorical variables were expressed as proportions. The significance of differences between proportions or percentages was determined by the Chi-square test or Fisher's exact test when the expected value was less than 5 . Urinary proteins were $\log$ transformed due to a skewed distribution, when analysis of covariance (ANCOVA) was used to adjust for age, diagnosis or other covariates.

We next examined the predictive value of each urinary protein marker for severe renal histological lesions by logistic regression analysis on log-transformed data. Model fit was assessed with the Hosmer-Lemeshow goodnessof-fit test. A non-significant value for the Hosmer-Lemeshow chi-square test suggests an absence of biased fit. A receiver operating characteristic (ROC) curve was constructed and the area under the ROC curve (AUC) was calculated to assess the predictive strength. The nonparametric method of Delong was used to compare difference between AUCs [27]. Optimal cut-off points to maximize 
Table 1 Patient characteristic at the time of renal biopsy

\begin{tabular}{|c|c|c|c|c|c|}
\hline Characteristics & & $\begin{array}{l}\operatorname{IgAN} \\
n=40\end{array}$ & $\begin{array}{l}\operatorname{lgMN} \\
\mathrm{n}=37\end{array}$ & $\begin{array}{c}\text { MesPGN } \\
\text { without } \lg A / \lg M \\
n=21\end{array}$ & $P$ \\
\hline Age, years & & $10.2[3.9-15]$ & $9.4[3.9-13.6]$ & $6.2[2.8-13.2]$ & .002 \\
\hline Sex, male/ female & & $28 / 12$ & 20/17 & $10 / 11$ & NS \\
\hline Body weight, kg & & $33.5[15.5-71]$ & $27[14-62.5]$ & 20 [14-65] & .015 \\
\hline Duration of disease prior to biopsy, months & & 2 [0.23-120] & $12[0.33-84]$ & $6[0.67-48]$ & .012 \\
\hline Hematuria, n (\%) & & $39(98)$ & $36(97)$ & $21(100)$ & NS \\
\hline Macro hematuria, $\mathrm{n}(\%)$ & & $25(63)$ & $7(19)$ & $4(19)$ & .000 \\
\hline Proteinuria $>4 \mathrm{mg} / \mathrm{m}^{2} / \mathrm{h}, \mathrm{n}(\%)$ & & $27(68)$ & $18(49)$ & $11(52)$ & NS \\
\hline Proteinuria $>40 \mathrm{mg} / \mathrm{m}^{2} / \mathrm{h}, \mathrm{n}(\%)$ & & $16(40)$ & $8(22)$ & $4(19)$ & NS \\
\hline Serum creatinine $>1.5 \mathrm{mg} / \mathrm{dl}, \mathrm{n}(\%)$ & & $1(3)$ & $0(0)$ & $0(0)$ & NS \\
\hline Hypertension ${ }^{\mathrm{a}}, \mathrm{n}(\%)$ & & $4(10)$ & $2(5)$ & $2(10)$ & NS \\
\hline \multirow[t]{5}{*}{ Clinical features, n (\%) } & Isolated hematuria & $13(33)$ & $19(51)$ & $10(48)$ & NS \\
\hline & Proteinuria with or without hematuria & $18(45)$ & $10(27)$ & $6(29)$ & NS \\
\hline & Nephritic syndrome ${ }^{b}$ & $2(5)$ & $1(3)$ & $0(0)$ & NS \\
\hline & Nephrotic syndrome ${ }^{c}$ & $6(15)$ & $7(19)$ & $5(24)$ & NS \\
\hline & Acute kidney injury $^{d}$ & $1(3)$ & $0(0)$ & $0(0)$ & NS \\
\hline \multirow[t]{15}{*}{ Histological features, n (\%) } & Adhesion & $12(30)$ & $8(22)$ & $8(38)$ & NS \\
\hline & Sclerosis & $5(13)$ & $0(0)$ & $1(5)$ & NS \\
\hline & Crescent & $1(3)$ & $0(0)$ & $0(0)$ & NS \\
\hline & Endocapillary hypercellularity & $8(20)$ & $2(5)$ & $3(14)$ & NS \\
\hline & Tubular atrophy & $9(23)$ & $5(14)$ & $4(19)$ & NS \\
\hline & Interstitial fibrosis & $2(5)$ & $2(5)$ & $1(5)$ & NS \\
\hline & Interstitial inflammation & $6(15)$ & $4(11)$ & $2(10)$ & NS \\
\hline & Arteriolar lesions & $0(0)$ & $0(0)$ & $0(0)$ & NS \\
\hline & Severe MC (score $\geq 2)^{e}$ & $20(50)$ & $9(24)$ & $5(24)$ & .030 \\
\hline & Severe GS $(\text { score } \geq 2)^{f}$ & $9(23)$ & $5(14)$ & $3(14)$ & NS \\
\hline & Severe TID $(\text { score } \geq 2)^{g}$ & $11(28)$ & $5(14)$ & $4(19)$ & NS \\
\hline & Severe MC + severe GS & $6(15)$ & $2(5)$ & $2(10)$ & NS \\
\hline & Severe $M C+$ severe TID & $6(15)$ & $2(5)$ & $2(10)$ & NS \\
\hline & Severe GS + severe TID & $5(13)$ & $3(8)$ & $0(0)$ & NS \\
\hline & Severe MC + GS + TID & $3(8)$ & $1(3)$ & $0(0)$ & NS \\
\hline \multirow[t]{2}{*}{ Treatmen, n (\%) } & Prednisone & $18(45)$ & $14(38)$ & $7(33)$ & NS \\
\hline & Cyclophosphamide & $4(10)$ & $3(8)$ & $3(14)$ & NS \\
\hline
\end{tabular}

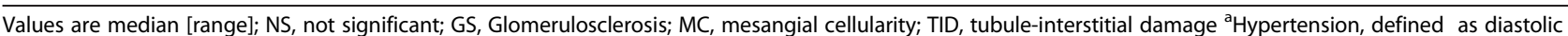
and/or systolic pressure higher than the 95th percentile for age, sex, and height percentile. ${ }^{b}$ Nephritic syndrome, defined as hematuria, red blood cell casts, proteinuria, and/or renal insufficiency, and/or hypertension. ${ }^{c}$ Nephrotic syndrome, defined as $24-\mathrm{h}$ proteinuria $>40 \mathrm{mg} / \mathrm{m}^{2} / \mathrm{h}$ and serum albumin level $<2.5 \mathrm{~g} / \mathrm{dl}$. ${ }^{\mathrm{d}}$ Acute kidney injury, defined as a $\geq 50 \%$ decrease in estimated creatinine clearance, based on Schwartz formula. ${ }^{\mathrm{e} S e v e r e} \mathrm{MC}$ (score $\geq 2$ ), defined as $>5$ mesangial cells/ mesangial area. 'Severe GS (score $\geq 2$ ), defined as $\geq 10 \%$ glomeruli showing segmental adhesions or sclerosis. ${ }^{9}$ Severe TID (score $\geq 2$ ), defined as focal or diffuse tubular and interstitial lesions

both sensitivity and specificity were also determined. The difference with $p$ values $<0.05$ was considered to be statistically significant. All probability values are two-sided.

\section{Results}

\section{Patient characteristics}

Clinical data at the time of renal biopsy and histopathological findings in 98 children with MesPGN are shown in Table 1. Of total 98 children, 40 were diagnosed with IgAN, 37 with IgMN, and 21 with MesPGN without
IgA/IgM being deposited in the mesangium on immunofluorescent microscopy. Data were compared among children with IgAN, IgMN and MesPGN without IgA/ IgM in Table 1. No significant difference was found in the frequency of the five categories of renal manifestations, although there was a significant difference with regard to age and body weight among groups. There was a significant difference among three groups for the frequency of mild and severe MC: $50 \%$ of children with IgAN, $76 \%$ with IgMN, and $76 \%$ with MesPGN without 
Table 2 Comparison of urinary proteins among children with $\lg A N$, IgMN and MesPGN without $\lg A / \lg M$

\begin{tabular}{|c|c|c|c|c|}
\hline Urinary protein markers & $\lg A N n=40$ & $\lg M N \mathrm{n}=37$ & $\begin{array}{c}\text { MesPGN without } \\
\lg A / \lg M n=21\end{array}$ & $P$ \\
\hline $\mathrm{u} \lg \mathrm{g}(\mathrm{mg} / \mathrm{g} \mathrm{uCr})$ & $65.2[2.6-926.7]$ & $6.5[0.2-397.1]$ & $9.8[1.6-842.4]$ & NS \\
\hline u Albumin (mg/g uCr) & 372.8 [8-2937] & $24.6[4-1764]$ & $53.4[6-3300]$ & $.021^{*}$ \\
\hline u Transferrin (mg/g uCr) & $63.7[0.5-441.7]$ & $2.5[0.4-804.1]$ & $4.8[0.3-936.2]$ & NS \\
\hline $\mathrm{u} \mathrm{a}_{1}$-microglobulin (mg/g uCr) & $9.5[0.1-234.9]$ & $5.0[1.1-104.5]$ & $5.5[0.7-84.9]$ & NS \\
\hline $\mathrm{u} \beta_{2}$-microglobulin (mg/g uCr) & $0.4[0.1-3.0]$ & $0.4[0.1-1.4]$ & $0.4[0.0-4.1]$ & NS \\
\hline u NAG (u/g uCr) & $17.8[4.5-172.0]$ & $7.6[2.1-47.8]$ & $11.8[1.8-48.6]$ & NS \\
\hline 24-h Proteinuria $\left(\mathrm{mg} / \mathrm{m}^{2} / \mathrm{h}\right)$ & $37.0[2.0-257.0]$ & $4.4[0.5-335.0]$ & $37.2[4.1-197.3]$ & NS \\
\hline
\end{tabular}

Values are median [range]; NAG: $N$-acetyl- $\beta$-glucosaminidase; NS, not significant

*The difference did not remain significant after adjustment for age using ANCOVA analysis. The level of urinary proteins was log-transformed for ANCOVA analysis

IgA/IgM had a mild MC defined as 4-5 mesangial cells on per mesangial area $($ score $=1)$. The frequency of severe MC defined as $>5$ mesangial cells/mesangial area (score $\geq 2$ ) was significant higher in children with IgAN.

\section{Comparison of urinary protein markers among children with IgAN, IgMN and MesPGN without $\lg A / \lg M$}

In Table 2, the level of urinary albumin was significantly higher in children with IgAN as compared to those with IgMN, and those with MesPGN without IgA/IgM. The difference, however, did not remain significant after adjustment for age using ANCOVA analysis.

\section{Comparison of clinical and laboratory parameters between} children with mild and severe renal histological lesions Of total 98 patients with MesPGN, 34 had severe MC (score $\geq 2$ ) defined as $>5$ mesangial cells/ mesangial area; 17 had severe glomerulosclerosis (score $\geq 2$ ) defined as $\geq 10 \%$ glomeruli showing segmental adhesions or sclerosis; and 20 had severe tubule-interstitial damage (TID) (score $\geq 2$ ) defined as focal or diffuse tubular and interstitial lesions.

Comparison of clinical and laboratory parameters between children with mild (score $<2, \mathrm{n}=64$ ) and severe MC (score $\geq 2, n=34$ ), between mild (score $<2, n=81$ ) and severe glomerulosclerosis (score $\geq 2, \mathrm{n}=17$ ), and between mild (score $<2, \mathrm{n}=78$ ) and severe TID (score $\geq 2$, $\mathrm{n}=20$ ) is shown in Table 3 .

\section{Comparison of urinary protein markers between children with mild and severe renal histological lesions}

As shown in Figure 1, there was a significantly higher urinary level of IgG, albumin, transferrin, $\alpha 1$-microglobulin and NAG in children with severe MC (score $\geq 2)$ when compared with children with mild MC (score $<2$ ). The urinary level of IgG, albumin and transferrin in children with severe glomerulosclerosis (score $\geq 2$ ) was significantly higher in comparison to children with glomerulosclerosis score $<2$. The urinary level of IgG, albumin, transferrin and NAG was also significantly higher in children with severe TID (score $\geq 2$ ), as compared to children without or with mild TID (score $<2$ ). In Figure 1, data were log transformed.

Association of urinary protein markers with MC, glomerulosclerosis and TID

Urinary protein markers from all patients with MesPGN $(\mathrm{n}=98)$ were analyzed to predict severe MC, glomerulosclerosis and TID.

Logistic regression analysis identified that the urinary excretion of IgG, albumin, transferrin, $\alpha 1$-microglobulin and 24-h total protein was independently associated with severe $\mathrm{MC}$ defined as $>5$ mesangial cells/ mesangial area (Table 4). The urinary level of $\beta 2$-microglobulin and NAG was, however, not significantly associated with MC $(p>0.05)$.

Urinary transferrin and 24-h proteinuria were independent factors associated with severe glomerulosclerosis defined as $\geq 10 \%$ glomeruli showing segmental adhesions or sclerosis (Table 4). In contrast, urinary level of IgG, albumin, $\alpha 1$-microglobulin, $\beta 2$-microglobulin and NAG was not significantly associated with glomerulosclerosis $(p>0.05)$.

Meanwhile, urinary transferrin and NAG were independently associated with severe TID defined as focal or diffuse tubular and interstitial lesions (Table 4). Urinary level of IgG, albumin, $\alpha 1$-microglobulin and $\beta 2$-microglobulin, as well as 24-h proteinuria was, however, not significantly associated with TID in children with MesPGN $(p>0.05)$.

The odds ratio for predicting severe MC, glomerulosclerosis, and TID is shown in Table 4. The association remained significant after adjustment for age, clinical features, histological diagnosis or treatment with prednisone and cyclophosphamide as shown in Table 4.

\section{Ability of urinary protein markers to predict severe MC, glomerulosclerosis, and TID}

In Table 5, urinary transferrin displayed the highest AUC of 0.86 ( $p=0.000)$, followed by albumin, $\alpha 1$-microglobulin, IgG and 24-h proteinuria to predict severe MC by using ROC analysis. When combined with other 
Table 3 Comparison of clinical and laboratory parameters between children with mild and severe renal histological lesions

\begin{tabular}{|c|c|c|c|c|c|c|c|c|c|}
\hline & \multicolumn{3}{|c|}{ Mesangial cellularity } & \multicolumn{3}{|c|}{ Glomerulosclerosis } & \multicolumn{3}{|c|}{ Tubule-interstitial damage } \\
\hline & Mild & Severe & $P$ & Mild & Severe & $P$ & Mild & Severe & $P$ \\
\hline Number of patients & 64 & 34 & & 81 & 17 & & 78 & 20 & \\
\hline Age, years & $9.5[2.8-15]$ & 9.8 [3.9-15] & NS & $9.1[2.8-15]$ & $10.4[4.1-14.3]$ & NS & $8.5[2.8-15]$ & $11.7[3.1-15]$ & .001 \\
\hline Sex (male/ female) & $36 / 28$ & $22 / 12$ & NS & $48 / 33$ & $10 / 7$ & NS & $43 / 35$ & $15 / 5$ & NS \\
\hline Body weight, kg & $30[14-71]$ & $31.5[15-65]$ & NS & $27.5[14-71$ & 32 [15.5-57] & NS & 27 [14-65] & $37[17-71]$ & .003 \\
\hline \multicolumn{10}{|c|}{ Histological diagnosis, n (\%) } \\
\hline IgAN & $20(31)$ & $20(59)$ & .008 & $31(38)$ & $9(53)$ & NS & $29(37)$ & $11(55)$ & NS \\
\hline $\lg M N$ & $28(44)$ & $9(26)$ & NS & $32(40)$ & $5(29)$ & NS & $32(41)$ & $5(25)$ & NS \\
\hline MesPGN(IgA- IgM-) & $16(25)$ & $5(15)$ & NS & $18(22)$ & $3(18)$ & NS & $17(22)$ & $4(20)$ & NS \\
\hline \multicolumn{10}{|c|}{ Clinical features* n (\%) } \\
\hline Mild & $55(86)$ & $21(62)$ & .006 & $65(80)$ & $11(65)$ & NS & $61(78)$ & $15(75)$ & NS \\
\hline Severe & $9(14)$ & $13(38)$ & .006 & $16(20)$ & $6(35)$ & NS & $17(22)$ & $5(25)$ & NS \\
\hline \multicolumn{10}{|l|}{ Hematuria n (\%) } \\
\hline 5-10RBC/HPF & $11(17)$ & $2(6)$ & NS & $12(15)$ & $1(6)$ & NS & $10(13)$ & $3(15)$ & NS \\
\hline 10-30RBC/HPF & $36(56)$ & $23(68)$ & NS & $47(58)$ & $12(71)$ & NS & $43(55)$ & $16(80)$ & NS \\
\hline$>30 \mathrm{RBC} / \mathrm{HPF}$ & $16(25)$ & $8(24)$ & NS & $21(26)$ & $3(18)$ & NS & $23(29)$ & $1(5)$ & .021 \\
\hline \multicolumn{10}{|l|}{ Proteinuria, n (\%) } \\
\hline$>4 \mathrm{mg} / \mathrm{m}^{2} / \mathrm{h}$ & $29(45)$ & $27(79)$ & .001 & $42(52)$ & $14(82)$ & .021 & $44(56)$ & $12(60)$ & NS \\
\hline$>40 \mathrm{mg} / \mathrm{m}^{2} / \mathrm{h}$ & $11(17)$ & $17(50)$ & .001 & $18(22)$ & $10(59)$ & .002 & $19(24)$ & $9(45)$ & NS \\
\hline Prednisone, n (\%) & $18(28)$ & $21(62)$ & .001 & $27(33)$ & $12(71)$ & .004 & $28(36)$ & $11(55)$ & NS \\
\hline Cyclophosphamide & $4(6)$ & $6(18)$ & NS & $5(6)$ & $5(29)$ & .013 & $6(8)$ & $4(20)$ & NS \\
\hline
\end{tabular}

Values are median [range]; NS, not significant.

Mild mesangial cellularity is defined as 4-5 mesangial cells on per mesangial area (score $<2$ ); severe is defined as $>5$ mesangial cells on per mesangial area (score $\geq 2$ ). Mild glomerulosclerosis is defined as absent or less than $10 \%$ of all biopsied glomeruli showing segmental adhesions or sclerosis (score $<2$ ); severe is defined as $\geq 10 \%$ glomeruli showing segmental adhesions or sclerosis (score $\geq 2$ ).

Mild tubule-interstitial damage is defined as tubular and interstitial lesions absent or very mildly focal (score $<2$ ); severe is defined as focal or diffuse tubular and interstitial lesions (score $\geq 2$ ).

*Clinical features: the patients were classified into five categories according to their renal manifestations at the time of biopsy: (1) micro- or macroscopic hematuria; (2) asymptomatic proteinuria with or without hematuria; (3) acute nephritic syndrome; (4) nephrotic syndrome; (5) Acute kidney injury. Classes 1 and 2 were considered as mild clinical features, and classes 3-5 as severe.

urinary protein markers, the performance was not significantly better than urinary transferrin alone (the method of Delong, $p>0.05$ ).

Severe glomerulosclerosis was significantly predicted by urinary transferrin $(\mathrm{AUC}=0.82, p=0.007)$ and 24 -h proteinuria (AUC $=0.79, p=0.014$ ). When combined with 24$\mathrm{h}$ proteinuria, the performance was not significantly better than urinary transferrin alone $(p>0.05)$. Urinary NAG level was significantly predictive of severe TID (AUC= $0.82, p=0.004)$, and better than urinary transferrin (AUC $=0.74, p=0.030$ ). When combining both markers, the performance improved (AUC $=0.92, p=0.003$ ) over that of urinary NAG alone, but not reaching statistical significance $(p>0.05)$.

The sensitivity and specificity of urinary protein markers to predict severe MC, glomerulosclerosis, and TID based on optimal cut-off value

In Table 5, we also calculated the cut-off value for urinary proteins to predict severe $\mathrm{MC}$, glomerulosclerosis and TID. Urinary transferrin displayed sensitivity $88 \%$ and specificity $74 \%$ at the optimal cut-off value of $45 \mathrm{mg} / \mathrm{g} \mathrm{uCr}$ to predict severe MC. The optimal cut-off value for urinary transferrin to predict severe glomerulosclerosis was $136 \mathrm{mg} / \mathrm{g} \mathrm{uCr}$ (sensitivity $100 \%$, specificity $74 \%)$. At the optimal cut-off value of $25 \mathrm{u} / \mathrm{g} \mathrm{uCr}$ to predict severe TID, urinary NAG displayed sensitivity $75 \%$ and specificity $77 \%$.

\section{Discussion}

In this study of children with MesPGN, we analyzed the predictive value of 6 candidate urinary proteins measured at the same time as renal biopsy, for the detection of severe renal histological lesions. Our data suggest that urinary protein markers, which have been used widely in clinic, might be useful to predict the development and progression of renal histological lesions in children with MesPGN. Mesangial cellularity, percentage of glomeruli showing segmental adhesions or sclerosis, and percentage of tubular atrophy/interstitial fibrosis were used in 

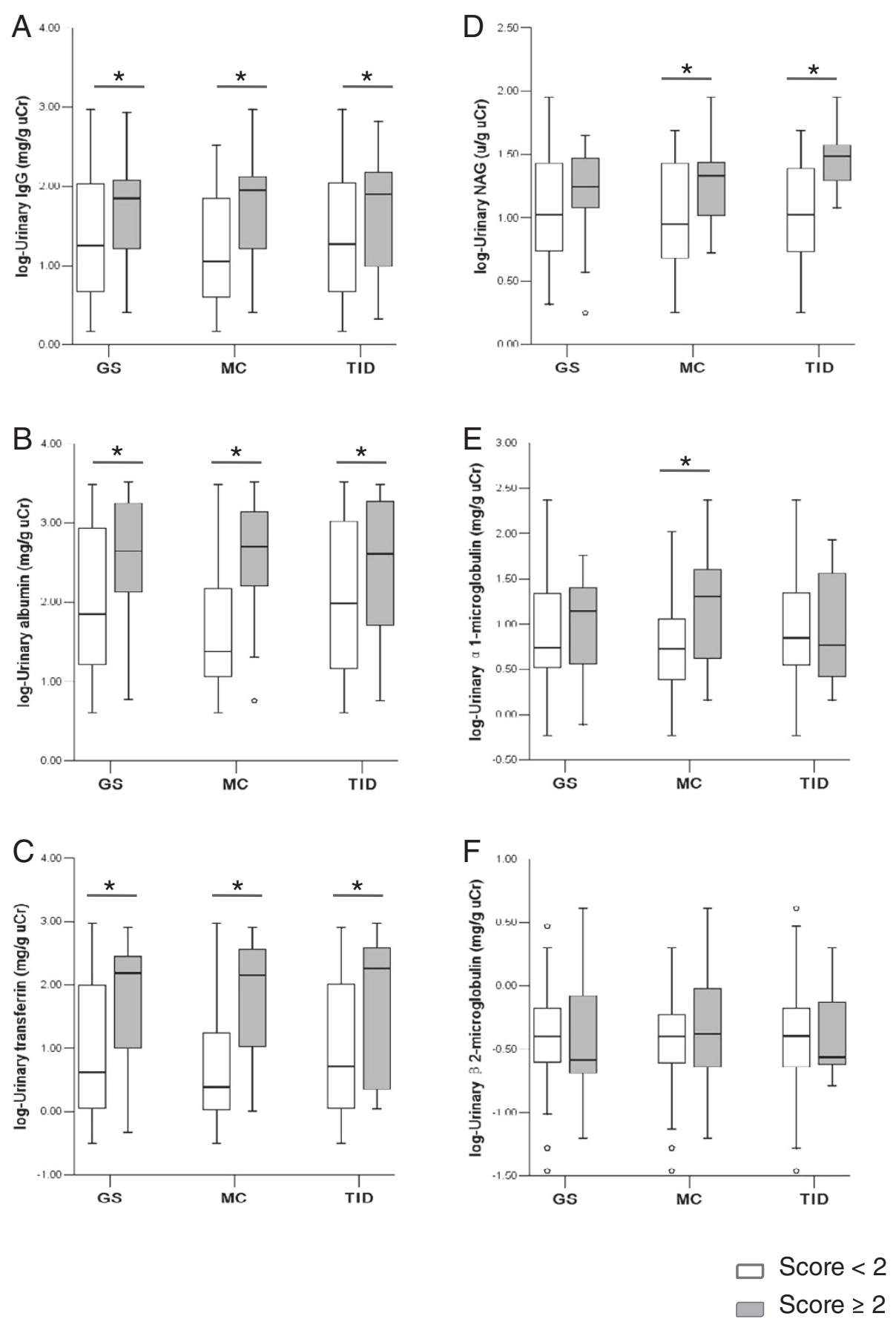

Figure 1 Comparison of urinary protein markers between children with mild and severe renal histological lesions. Comparison of urinary proteins between children with severe mesangial cellularity (MC) defined as $>5$ mesangial cells/ mesangial area (score $\geq 2, n=34$ ) and those with mild $M C$ (score $<2, n=64$ ); between children with severe glomerulosclerosis (GS) defined as $\geq 10 \%$ glomeruli showing segmental adhesions or sclerosis (score $\geq 2, n=17$ ) and those with mild GS (score $<2, n=81$ ); and between children with severe tubule-interstitial damage (TID) defined as focal or diffuse tubular and interstitial lesions (score $\geq 2, n=20$ ) and those with mild TID (score $<2, n=78$ ). Urinary excretion of IgG (A), albumin (B), transferrin (C), NAG (D), a1-microglobulin (E) and $\beta 2$-microglobulin (F) was log transformed. Values are medians, boxes represent interquartile range, whiskers indicate smallest and largest non-outlier observation, and circles indicate outliers. Probability values: two-sample Kolmogorov-Smirnov test, ${ }^{*} p<0.05$. 
Table 4 Association of urinary proteins with renal histological lesions

\begin{tabular}{|c|c|c|c|}
\hline & Odds ratio & $95 \% \mathrm{Cl}$ & $P^{*}$ \\
\hline \multicolumn{4}{|l|}{ Mesangial cellularity } \\
\hline $\mathrm{u} \operatorname{lgG}(\mathrm{mg} / \mathrm{g} \mathrm{uCr})$ & 2.86 & $1.36-6.03$ & .006 \\
\hline u Albumin (mg/g uCr) & 3.57 & $1.80-7.07$ & .000 \\
\hline u Transferrin (mg/g uCr) & 2.90 & $1.64-5.12$ & .000 \\
\hline $\mathrm{u} \mathrm{a}_{1}$-microglobulin (mg/g uCr) & 2.85 & $1.13-7.21$ & .027 \\
\hline 24-h Proteinuria $\left(\mathrm{mg} / \mathrm{m}^{2} / \mathrm{h}\right)$ & 2.79 & $1.15-6.81$ & .024 \\
\hline \multicolumn{4}{|l|}{ Glomerulosclerosis } \\
\hline u Transferrin (mg/g uCr) & 1.86 & $1.03-3.36$ & .038 \\
\hline 24-h Proteinuria $\left(\mathrm{mg} / \mathrm{m}^{2} / \mathrm{h}\right)$ & 5.16 & $1.37-19.43$ & .015 \\
\hline \multicolumn{4}{|l|}{ Tubule-interstitial damage } \\
\hline u Transferrin (mg/g uCr) & 1.89 & $1.01-3.54$ & .048 \\
\hline u NAG (mg/g uCr) & 45.39 & $2.10-980$ & .015 \\
\hline
\end{tabular}

The level of urinary proteins was log-transformed due to a skewed distribution Odds ratio represents the increase in odds per log increase in the level of urinary proteins.

* The association remained significant after adjustment for potential confounders, including age, clinical features, histological diagnosis or treatment with prednisone and cyclophosphamide.

our study to evaluate renal histological lesions in children with MesPGN. The semi-quantitative scoring system has been utilized in previous reports $[15,25,26]$. According to the oxford classification of IgA nephropathy, several pathologic features could be used to interrogate prognostic significance independent of the clinical data in IgAN, which are likely to be applicable to other types of glomerulonephritis. Four of these features, including mesangial hypercellularity, glomerulosclerosis, tubular atrophy and interstitial fibrosis, were subsequently shown to have independent value in predicting renal outcome $[15,16]$. Furthermore, glomerulosclerosis and tubular atrophy/interstitial fibrosis are considered to be the most powerful histological predictors for the progression to ESRD in both children and adults with glomerular diseases [17-21].

Our data demonstrated that the urinary excretion of transferrin, albumin, $\alpha 1$ - microglobulin, IgG and 24-h total protein could predict severe proliferation of mesangial cells in children with MesPGN. Urinary transferrin and 24-h proteinuria were independent factors associated with the development of glomerulosclerosis.

In our study, urinary transferrin has an increased predictive value relative to other urinary proteins as assessed by AUC, predicting the severity of mesangial cellularity and glomerulosclerosis in children with MesPGN. To our knowledge, urinary transferrin has not been studied as a marker to detect the severity of renal histological lesions. Urinary transferrin, which results from abnormal permeability of the glomerular basement membrane, is suggested to be a marker for early stages of glomerular diseases. Transferrin is very similar to albumin in molecular weight but has a higher isoelectric point. Increased urinary transferrin excretion may precede the development of microalbuminuria in glomerular diseases [28]. Although there was a significantly higher urinary level of albumin in children with severe glomerulosclerosis as compared to children with mild glomerulosclerosis, urinary albumin was not significantly associated with glomerulosclerosis by logistic regression analysis in the present study. Our result indicates that urinary transferrin may predict the severity of mesangial cellularity and glomerulosclerosis in the early stages of potentially progressive glomerular diseases.

Tubular atrophy/interstitial fibrosis are due to the increased protein traffic across the tubular cells in

Table 5 Predictive characteristics of urinary proteins for severe renal histological lesions

\begin{tabular}{|c|c|c|c|c|c|c|}
\hline & AUC & $95 \% \mathrm{Cl}$ & $P$ & Optimal cut-off value & Sensitivity (\%) & Specificity (\%) \\
\hline \multicolumn{7}{|c|}{ Severe mesangial cellularity } \\
\hline u Transferrin & 0.86 & $0.74-0.99$ & .000 & $45 \mathrm{mg} / \mathrm{g} \mathrm{uCr}$ & 88 & 74 \\
\hline u Albumin & 0.79 & $0.64-0.95$ & .003 & $372 \mathrm{mg} / \mathrm{g} \mathrm{uCr}$ & 82 & 74 \\
\hline $\mathrm{u} \mathrm{a}_{1}$-microglobulin & 0.78 & $0.62-0.94$ & .005 & $22 \mathrm{mg} / \mathrm{g} \mathrm{uCr}$ & 82 & 74 \\
\hline $\mathrm{u} \mathrm{lgG}$ & 0.77 & $0.61-0.92$ & .006 & $65 \mathrm{mg} / \mathrm{g} \mathrm{uCr}$ & 77 & 74 \\
\hline 24-h Proteinuria & 0.78 & $0.63-0.93$ & .004 & $32 \mathrm{mg} / \mathrm{m}^{2} / \mathrm{h}$ & 77 & 68 \\
\hline \multicolumn{7}{|c|}{ Severe glomerulosclerosis } \\
\hline u Transferrin & 0.82 & $0.68-0.95$ & .007 & $136 \mathrm{mg} / \mathrm{g} \mathrm{uCr}$ & 100 & 74 \\
\hline 24-h Proteinuria & 0.79 & $0.64-0.93$ & .014 & $40 \mathrm{mg} / \mathrm{m}^{2} / \mathrm{h}$ & 88 & 61 \\
\hline \multicolumn{7}{|c|}{ Severe tubule-interstitial damage } \\
\hline u NAG & 0.82 & $0.69-0.94$ & .004 & $25 \mathrm{u} / \mathrm{g} \mathrm{uCr}$ & 75 & 77 \\
\hline u Transferrin & 0.74 & $0.54-0.94$ & .030 & $97 \mathrm{mg} / \mathrm{g} \mathrm{uCr}$ & 75 & 77 \\
\hline
\end{tabular}

$\mathrm{AUC}$, area under the receiver-operating-characteristic curve; $\mathrm{Cl}$, confidence interval.

Severe mesangial cellularity, defined as $>5$ mesangial cells on per mesangial area.

Severe glomerulosclerosis, defined as $\geq 10 \%$ glomeruli showing segmental adhesions or sclerosis.

Severe tubule-interstitial damage, defined as focal or diffuse tubular and interstitial lesions. 
glomerular diseases. Accumulated evidence suggests that abnormally filtered proteins reaching the tubular lumen might be responsible for the injury of tubular cells, triggering the release of several proinflammatory cytokines, which cause interstitial inflammatory infiltration and fibrosis $[14,20,29,30]$. Urinary NAG, which results from the increased excretion of an isoenzyme synthesized in the tubular cells exposed to various toxic substances is useful for the detection of tubulointerstitial damage in children with MesPGN in our study. This result is in agreement with previous studies [26,31]. It has also been showed that increased NAG excretion, associated with increased transferrin excretion could occur even in the absence of morphological evidence of tubular cells damage $[26,31,32]$.

In previous studies, the urinary excretion of $\alpha 1$ microglobulin, $\beta 2$ - microglobulin and IgG is also considered a marker for detection of tubular lesions in patients with glomerular diseases by correlation analysis $[14,22,26]$. Our study confirmed the correlation of various urinary proteins, except $\beta 2$ - microglobulin, with tubulointerstitial damage in children with MesPGN (Spearman's correlation test, data not shown). However, by binary logistic regression analysis, only urinary excretion of NAG and transferrin, but not that of IgG, albumin, $\alpha 1-$ microglobulin and $\beta 2$ - microglobulin, was significantly associated with the extent of tubulointerstitial damage.

To our knowledge, this is the first study to analyze the predictive value of urinary proteins measured at the same time as biopsy for the detection of severe renal histological lesions in children with MesPGN. Unfortunately, there were a number of limitations to our study. First, the relatively small sample size limited the power to perform logistic regression in the subgroup of IgAN or IgMN. Notably, there was no significant difference in the level of urinary proteins among the subgroups. Second, mesangial hypercellularity, glomerulosclerosis, and tubule-interstitial damage are often mixing together in actual renal biopsy findings. A total scoring system for evaluating mesangial, glomerular, tubular, and interstitial injuries would provide more prognostic information than do individual component scores. Unfortunately, the relatively small sample size limited our ability to demonstrate a significant association between urine proteins and the severity of histological lesions of MesPGN assessed by using a total score for glomerular, tubular, and interstitial injuries. Third, this study was conducted in less severely ill patients. This may raise a question whether this association is also true for a typical group of patients with severe renal manifestations. Fourth, the majority of our patients $(76 \%)$ had isolated hematuria or asymptomatic proteinuria with or without hematuria. It may not be surprising that high-molecular-weight IgG, which may reveal a severe disruption of the permeability of the glomerular capillary wall, performed less well as a predictive test in our patient population.

\section{Conclusions}

In this study, urinary protein markers show a significant relationship with the severity of renal histological lesions. Urinary transferrin could, as an independent factor, predict severe mesangial cellularity and glomerulosclerosis. Urinary NAG could predict tubulointerstitial damage with greater accuracy than other urinary proteins in children with MesPGN. Our study suggests that on the follow-up examination, these findings have potential significance for understanding the histopathological lesions of glomeruli and tubulointerstitium in children with MesPGN without a renal biopsy. Urinary protein markers might be useful to predict the development and progression of renal histological lesions, and assist in evaluating the outcome and prognosis in children with MesPGN as non-invasive and easily repeatable indicators. Further follow-up studies are needed to confirm the association of urine protein markers and renal histological lesions with clinical outcome in children with MesPGN.

\section{Competing interests}

The authors declare that they have no competing interests.

\section{Acknowledgements}

This work was supported by grants from the National Natural Science Foundation of China (30972711), the National Natural Science Foundation of Jiangsu (BK2009128), and the Science and Technology Program of Suzhou (SYS201137). The authors acknowledge the doctors from the Department of Nephrology for their efforts in collecting renal biopsy samples, and the nurses for collecting urine samples.

\section{Author details}

${ }^{1}$ Institute of pediatric research, Children's Hospital of Soochow University, Suzhou, China. ${ }^{2}$ Department of nephrology, Children's Hospital of Soochow University, Suzhou, China. ${ }^{3}$ Department of pathology, Children's Hospital of Soochow University, Suzhou, China. ${ }^{4}$ Department of neonatology, Children's Hospital of Soochow University, Suzhou, China.

\section{Authors' contributions}

L.YH had primary responsibility for study design, data analysis and interpretation and writing of the manuscript. W. J helped to draft the manuscript. Z XM participated in interpretation of renal biopsy data. F. QH participated in data collecting. L. XZ and F. X had primary responsibility for study design and protocol development. All authors read and approved the final manuscript.

Received: 8 December 2011 Accepted: 20 May 2012

Published: 20 May 2012

\section{References}

1. D'Amico G: Influence of clinical and histological features on actuarial renal survival in adult patients with idiopathic lgA nephropathy, membranous nephropathy, and membranoproliferative glomerulonephritis: survey of the recent literature. Am J Kidney Dis 1992, 20(4):315-323.

2. Woo KT, Chan CM, Mooi CY HLC, Tan HK, Foo M, Lee GS, Anantharaman V, Lim CH, Tan CC: The changing pattern of primary glomerulonephritis in Singapore and other countries over the past 3 decades. Clin Nephrol 2010, 74(5):372-383. 
3. D'Amico G: The commonest glomerulonephritis in the world: $\lg \mathrm{A}$ nephropathy. Q J Med 1987, 64(245):709-727.

4. Barratt J, Smith AC, Molyneux K, Feehally J: Immunopathogenesis of IgAN Semin Immunopathol 2007, 29(4):427-443.

5. Barratt J, Feehally J: IgA nephropathy. J Am Soc Nephrol 2005, 16(7):20882097.

6. Hogg RJ: Idiopathic immunoglobulin A nephropathy in children and adolescents. Pediatr Nephrol 2010, 25(5):823-829.

7. Donadio JV, Grande JP: IgA nephropathy. N Engl J Med 2002, 347(10):738748 .

8. Manno C, Strippoli GF, D'Altri C, Torres D, Rossini M, Schena FP: A nove simpler histological classification for renal survival in IgA nephropathy: a retrospective study. Am J Kidney Dis 2007, 49(6):763-775.

9. Little MA, Dorman A, Gill D, Walshe JJ: Mesangioproliferative glomerulonephritis with lgM deposition: clinical characteristics and outcome. Ren Fail 2000, 22(4):445-457.

10. Myllymaki J, Saha H, Mustonen J, Helin H, Pasternack A: IgM nephropathy: clinical picture and long-term prognosis. Am J Kidney Dis 2003 41(2):343-350

11. Alexopoulos E, Papagianni A, Stangou M, Pantzaki A, Papadimitriou M: Adult-onset idiopathic nephrotic syndrome associated with pure diffuse mesangial hypercellularity. Nephrol Dial Transplant 2000, 15(7):981-987.

12. Owada K, Suzuki H, Katoh T, Watanabe T: Genetical, histological, and clinical characteristics of IgA-negative mesangioproliferative glomerulopathy. Clin Exp Nephrol 2010, 14(1):56-62.

13. Remuzzi G, Bertani T: Pathophysiology of progressive nephropathies. $N$ Engl J Med 1998, 339(20):1448-1456.

14. D'Amico G, Bazzi C: Pathophysiology of proteinuria. Kidney Int 2003, 63(3):809-825

15. Roberts IS, Cook HT, Troyanov S, Alpers CE, Amore A, Barratt J, Berthoux F, Bonsib S, Bruijn JA, Cattran DC, et al: The Oxford classification of IgA nephropathy: pathology definitions, correlations, and reproducibility. Kidney Int 2009, 76(5):546-556.

16. Cattran DC, Coppo R, Cook HT, Feehally J, Roberts IS, Troyanov S, Alpers CE, Amore A, Barratt J, Berthoux F, et al: The Oxford classification of IgA nephropathy: rationale clinicopathological correlations, and classification. Kidney Int 2009, 76(5):534-545.

17. Katafuchi R, Oh Y, Hori K, Komota T, Yanase T, Ikeda K, Omura T, Fujimi S: An important role of glomerular segmental lesions on progression of IgA nephropathy: a multivariate analysis. Clin Nephrol 1994, 41(4):191-198.

18. Hogg RJ, Silva FG, Wyatt RJ, Reisch JS, Argyle JC, Savino DA: Prognostic indicators in children with $\lg A$ nephropathy-report of the Southwest Pediatric Nephrology Study Group. Pediatr Nephrol 1994, 8(1):15-20.

19. Nozawa R, Suzuki J, Takahashi A, Isome M, Kawasaki Y, Suzuki S, Suzuki H: Clinicopathological features and the prognosis of IgA nephropathy in Japanese children on long-term observation. Clin Nephrol 2005, 64(3):171-179.

20. Daniel L, Saingra Y, Giorgi R, Bouvier C, Pellissier JF, Berland Y: Tubular lesions determine prognosis of IgA nephropathy. Am J Kidney Dis 2000, 35(1):13-20.

21. Edstrom Halling S, Soderberg MP, Berg UB: Predictors of outcome in paediatric IgA nephropathy with regard to clinical and histopathological variables (Oxford classification). Nephrol Dial Transplant 2012, 27(2):715-722

22. Bazzi C, Petrini C, Rizza V, Arrigo G, D'Amico G: A modern approach to selectivity of proteinuria and tubulointerstitial damage in nephrotic syndrome. Kidney Int 2000, 58(4):1732-1741.

23. Bazzi C, Petrini C, Rizza V, Arrigo G, Beltrame A, Pisano L, D'Amico G: Urinary excretion of IgG and alpha(1)-microglobulin predicts clinical course better than extent of proteinuria in membranous nephropathy. Am J Kidney Dis 2001, 38(2):240-248.

24. Bazzi C, Rizza V, Raimondi S, Casellato D, Napodano P, D'Amico G: In crescentic $\lg A$ nephropathy, fractional excretion of $\lg G$ in combination with nephron loss is the best predictor of progression and responsiveness to immunosuppression. Clin J Am Soc Nephrol 2009 4(5):929-935.

25. Feehally J, Barratt J, Coppo R, Cook T, Roberts I: International IgA nephropathy network clinico-pathological classification of $\lg A$ nephropathy. Contrib Nephrol 2007, 157:13-18.
26. Bazzi C, Petrini C, Rizza V, Arrigo G, Napodano P, Paparella M, D'Amico G: Urinary $\mathrm{N}$-acetyl-beta-glucosaminidase excretion is a marker of tubular cell dysfunction and a predictor of outcome in primary glomerulonephritis. Nephrol Dial Transplant 2002, 17(11):1890-1896.

27. DeLong ER, DeLong DM, Clarke-Pearson DL: Comparing the areas under two or more correlated receiver operating characteristic curves: a nonparametric approach. Biometrics 1988, 44(3):837-845.

28. Bernard AM, Amor AA, Goemaere-Vanneste J, Antoine JL, Lauwerys RR, Lambert A, Vandeleene B: Microtransferrinuria is a more sensitive indicator of early glomerular damage in diabetes than microalbuminuria. Clin Chem 1988, 34(9):1920-1921.

29. Abbate M, Zoja C, Corna D, Capitanio M, Bertani T, Remuzzi G: In progressive nephropathies, overload of tubular cells with filtered proteins translates glomerular permeability dysfunction into cellular signals of interstitial inflammation. J Am Soc Nephrol 1998, 9(7):1213-1224.

30. Matsuo S, Morita Y, Mizuno M, Nishikawa K, Yuzawa Y: Proteinuria and damage to tubular cells-is complement a culprit? Nephrol Dial Transplant 1998, 13(11):2723-2726.

31. D'Amico G, Bazzi C: Urinary protein and enzyme excretion as markers of tubular damage. Curr Opin Nephrol Hypertens 2003, 12(6):639-643.

32. Kanauchi $M$, Akai $Y$, Hashimoto $T$ : Transferrinuria in type 2 diabetic patients with early nephropathy and tubulointerstitial injury. Eur J Intern Med 2002, 13(3):190-193.

doi:10.1186/1471-2369-13-29

Cite this article as: Li et al.: Urinary protein markers predict the severity of renal histological lesions in children with mesangial proliferative glomerulonephritis. BMC Nephrology 2012 13:29.

\section{Submit your next manuscript to BioMed Central and take full advantage of:}

- Convenient online submission

- Thorough peer review

- No space constraints or color figure charges

- Immediate publication on acceptance

- Inclusion in PubMed, CAS, Scopus and Google Scholar

- Research which is freely available for redistribution 